\title{
Clinical and molecular findings in 6 Turkish cases with Krabbe disease
}

\author{
Ayça Dilruba Aslanger ${ }^{1 \oplus}$, Esma Şengenç ${ }^{2 \oplus}$, Ayşe Betül Kölemen ${ }^{3 \oplus}$, \\ Emine Demiral $^{4 \oplus}$, Alpay Alkan ${ }^{5}$, Akın İşcan ${ }^{2 \oplus}$, Gözde Yeşil ${ }^{1 \oplus}$ \\ Departments of ${ }^{1}$ Medical Genetics ${ }^{2}$ Pediatric Neurology and ${ }^{5}$ Radiology, ${ }^{3}$ Bezmialem Vakıf University Faculty of Medicine, Istanbul; \\ ${ }^{4}$ Department of Medical Genetics, İstanbul Training and Research Hospital, İstanbul, Turkey.
}

\begin{abstract}
Background. Krabbe disease is a rare lysosomal storage disorder with a neurodegenerative course that occurs because of the deficiency of the beta-galactocerebrosidase (GALC) enzyme activity. The genetic basis of Krabbe disease consists of biallelic mutations in the GALC gene, but the genetic spectrum in the Turkish population is poorly defined. We aimed to present a Turkish case-series with infantile-onset Krabbe disease, define the clinical and molecular findings and compare the genetic spectrum with the mutations previously reported in the literature.
\end{abstract}

Methods. Six cases, who were referred to our clinic between 2015-2019, with a definite diagnosis of infantileonset Krabbe disease were included in the study. The family history, clinical information, biochemical and radiological examinations of the patients were screened and evaluated. All encoded exons and exon-intron regions of the GALC gene were sequenced using next generation sequencing technology. Multiplex ligationdependent probe amplification analysis was used for deletion type mutations that could not be detected by sequence analysis.

Results. GALC gene sequence analysis revealed four known mutations including c.1394C $>$ T (p.Thr465Ile), c.411_413delTAA (p.Lys139del), c.820G>C (p.Glu274Gln), and 30 kilobase deletion mutation among the exons 11-17 (IVS10del30kbp). Moreover, the c.1623G>A (p.Trp541Ter) variant, which was not previously reported in the literature, was detected in two cases.

Conclusions. We believe that the demonstration of the genetic spectrum of infantile-onset Krabbe disease in Turkish patients will be an important contribution to the GALC mutation data in our country. More importantly, two novel variants were defined. This knowledge may enable early detection and treatment with the advent of a carrier or newborn screening tests.

Key words: GALC gene, Krabbe disease, newborn screening tests.

Krabbe disease (KD), also known as globoid cell leukodystrophy (GCL; MIM \# 245200), is a life-threatening, autosomal-recessive neurodegenerative disease with a prevalence of $1 / 100,000-250,000 .{ }^{1}$ The main pathogenetic event is the progressive accumulation of galactoylceramide and galactosylsphingosine (psychosine) due to the lack of a lysosomal beta-

\footnotetext{
$\triangle$ Ayça Dilruba Aslanger

aaslanger@yahoo.com
}

Received 26th December 2020, revised 17th July 2021, 12th September 2021, accepted 7th November 2021. galactocerebrosidase (GALC) activity, which causes clinical findings related to increased apoptosis rate in myelin-forming cells. ${ }^{2}$

Nearly $90 \%$ of the cases are "early-onset (EO)" (infantile) KD cases, which often starts before 6 months. The remaining cases are "late-onset (LO)" KD which begin in the lateinfantile, juvenile, and adult period. In EOKD cases, hyperirritability, excessive crying, axial hypotonia, spasticity, gastroesophageal reflux, feeding difficulties, loss of acquired skills and peripheral neuropathy are observed. LOKD cases present with initial symptoms such as 
psychomotorregression, ataxia/gait disturbance, tremor, and febrile seizures between the ages of 7 months and 3 years. Infantile and late infantile forms progress rapidly, and cases die in the first 2-3 years of their lives. In the juvenile form, which has an age of onset between 3 and 8 years, the first finding is vision loss, which is followed by neuromotor regression and ataxia. Adult-onset cases are very heterogeneous, and the phenotype may be mild. ${ }^{2}$

For the definitive diagnosis of KD, it is sufficient to detect extremely low GALC activity in cases with clinical and radiological findings. In cranial magnetic resonance imaging (MRI) of EOKD, T2-weighted images show an involvement consistent with demyelination in the periventricular, deep white matter, dentate and cerebellar white matter. ${ }^{3}$ Occasionally optic nerve/chiasma hypertrophy may be involved. GALC enzyme activity is much lower than normal (less than $0-5 \%$ of normal). There is no correlation, however, between residual enzyme activity and phenotype. The genetic basis of $\mathrm{KD}$ is combined heterozygous or homozygous biallelic mutations in the GALC gene encoding the beta-galactocerebrosidase enzyme, which is a gene consisting of 17 exons localized to 14q31 and encoding 685 amino acids. So far, 275 mutations in the GALC gene have been reported in the HGMD (Human Genome Mutation Database) database (Professional subscription July 2021). Although in cases with well-known mutations there is a clear correlation between the genotype and phenotype, in cases with novel mutations it is difficult to predict the phenotype. Mutations causing KD are also thought to be population specific. In European populations, $30 \mathrm{~kb}$ deletion (IVS10del30kbp) is seen in $45 \%$ of cases, while $15 \%$ have c. $1586 \mathrm{C}>\mathrm{T}$ (p.Thr529Met), c.1700A $>$ C (p.Tyr567Ser) and c.1472delA (p.Lys491Argfs*62) mutations. ${ }^{4,5}$ Approximately $30 \%$ of Japanese Krabbe patients have c.683_694del12insCTC or c.2002C $>$ A mutations. ${ }^{6}$ However, the genetic spectrum in the Turkish population is poorly defined.

Early diagnosis of EOKD is crucial as it can lead to treatment with bone marrow or hematopoietic stem cell transplantation (HSCT). Since the risk of the disease being seen in the siblings of the affected patient is $25 \%$, the existence of a definite diagnosis is important to offer prenatal diagnosis options to the family.

In this report, we reviewed the molecular and clinical findings of six Turkish cases diagnosed with KD in the infantile period and compared their genetic profile with the published cases in the literature.

\section{Material and Methods}

Six cases, who were referred to Bezmialem Vakıf University Faculty of Medicine,Department of Medical Genetics outpatient clinic between 2015-2019, with a definite diagnosis of infantileonset KD were included in the study. The study was reviewed and approved by the Bezmialem Vakıf University, institutional review board, and written informed consent was obtained from all parents of the patients included in the study (No/Date: 54022451-050.05.04/05.02.2019). The family history, clinical information, biochemical and radiological examinations of the patients were screened and evaluated. The low activity of the GALC enzyme in patients' leukocytes was consistent with KD. Enzyme activity was determined as nmol MU/17h/ mg protein by fluorometric assay (Acıbadem Labmed, Istanbul, Turkey). DNA isolation was performed from EDTA blood samples taken from six cases and their available parents of five cases. All encoded exons and exon-intron regions of the GALC gene were sequenced using next generation sequencing technology (Miseq, Illumina Inc., San Diego, CA, USA). Multiplex ligation-dependent probe amplification (MLPA) analysis was used for deletion type mutations that could not be detected by sequence analysis (MRC-Holland SALSA MLPA P446-GALC). The presence of novel variants in the parents of the index cases were confirmed by Sanger sequence analysis. The final diagnosis was made by the reduced GALC activity in leukocytes, characteristic clinical and radiological findings as well as molecular findings. 


\section{Results}

\section{Overall patient characteristics}

Six patients from six families were included in this study. There were 4 males and 2 females. The age of onset was 2 months to 5 months. The mean age at the time of diagnosis was 6.5 months (range, 4 months to 12 months). Age of diagnosis was determined with the reporting date of GALC activity results. All cases died before 3 years of age. There was a consanguineous marriage between the parents of four cases, and the parents of the other cases were from the same or close village. The clinical, radiological, and molecular findings are summarized and compared with the previously published Turkish cases in Table I.
The initial findings observed in four out of six cases were psychomotor regression at 3 to 5 months, and hypotonia after 2 months of age in the remaining two cases. All patients had a history of hyperirritability and excessive crying, axial hypotonia and psychomotor retardation, and pathologic cranial MRI findings (Fig. 1).

\section{A brief summary of clinical findings}

Case 1, female patient, the third child of a consanguineous couple, was born at term by normal spontaneous vaginal delivery (NSVD). Family history revealed a deceased sister at 9 months and a paternal cousin with the diagnosis of KD. She had a healthy sister. The developmental milestones of her first three months were unremarkable. At that time, the

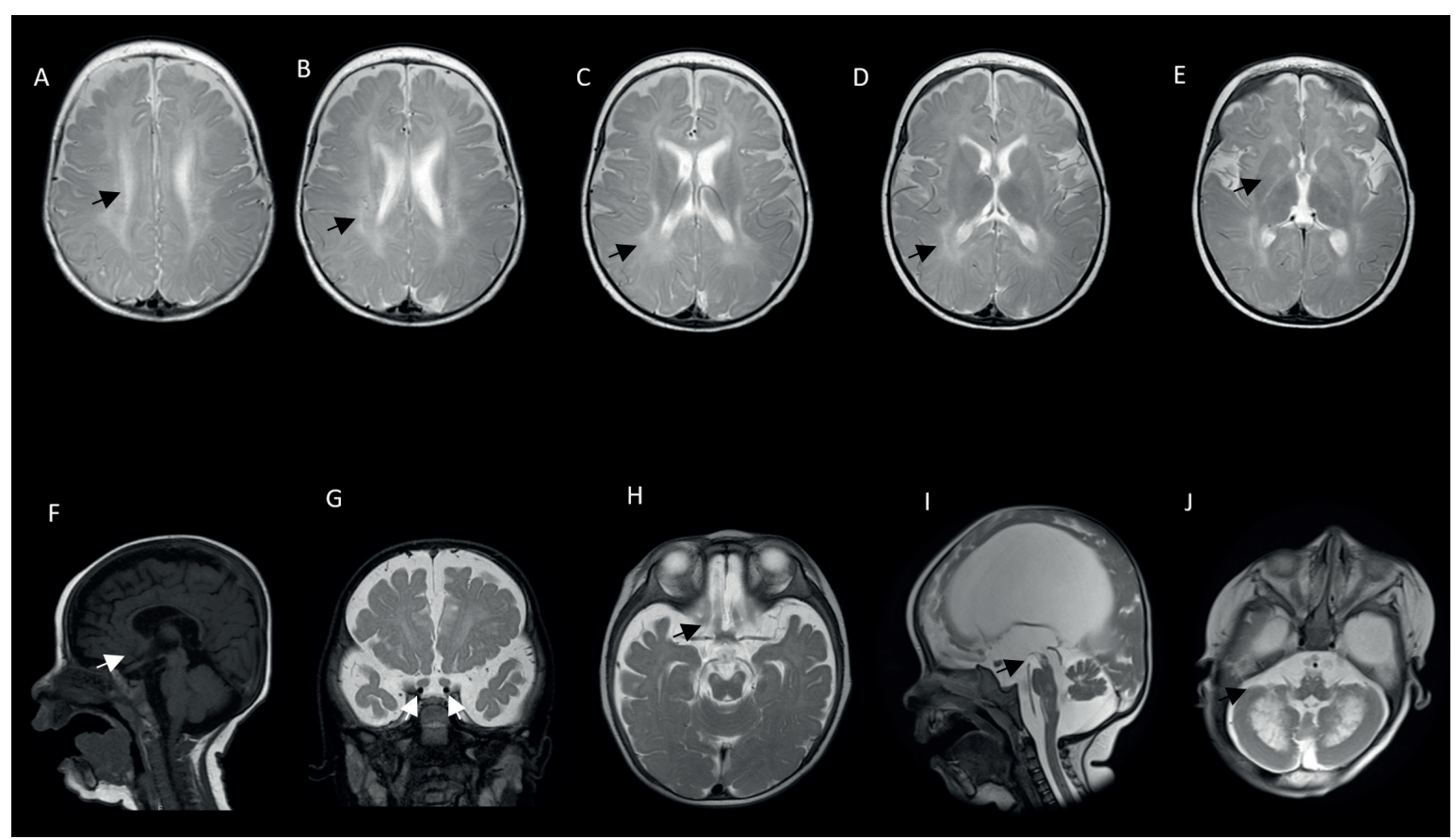

Fig. 1. Brain MRI findings in patients with Krabbe disease.

Patient \#2 Sagittal T2W images: hyperintense signal changes in deep cerebral white matter (periventricular/ centrum semiovale) in A-C and in posterior limb of internal capsule (PLIC) in D-E at 5 months (arrows).

Patient \#5 Axial T1W and coronal T2W MR images: atrophy of corpus callosum and diffuse hypertrophy of the optic nerves in F-G (arrows). Sagittal T2W image: bilaterally enlarged the proximal prechiasmatic optic nerves are bilaterally in $\mathbf{H}$ (arrow) at 11 months

Patient \#1 (I-J). Axial T2W image: volume loss of midbrain and severe dilation of the ventricles in I (arrow). Sagittal T2W MR images: hyperintense signal changes in dentate nucleus in J at 10 months (arrow). 
Table I. Combined data of our cases along with previously published early infantile Turkish cases.

\begin{tabular}{|c|c|c|c|c|c|}
\hline Case & $\mathrm{CM}$ & $\begin{array}{l}\text { Clinical findings at } \\
\text { the time of the first } \\
\text { visit }\end{array}$ & $\begin{array}{l}\text { GALC } \\
\text { enzyme } \\
\text { activity }\end{array}$ & MRI findings & Mutation results \\
\hline $\begin{array}{l}\text { Case } 1 \text { [ㅇ] } \\
\text { Age of OS: } 3 \text { mos } \\
\text { Age of Dx: } 4 \text { mos } \\
\text { DoD: } 14 \text { mos }\end{array}$ & yes & $\begin{array}{l}\text { irritability, crying, } \\
\text { feeding difficulties, } \\
\text { neuromotor } \\
\text { regression, } \\
\text { hypotonia }\end{array}$ & $\begin{array}{l}18 \mathrm{nmol} \\
\mathrm{MU} / 17 \mathrm{~h} / \\
\mathrm{mg} \text { protein* }\end{array}$ & $\begin{array}{l}\text { T2 hyperintense signal changes in PWM, } \\
\text { brainstem CST and cerebellar dentate nuclei. } \\
\text { Cerebral atrophy complicated with severe } \\
\text { dilation of the lateral and third ventricles, } \\
\text { diffuse brain atrophy including volume loss of } \\
\text { midbrain. }\end{array}$ & $\begin{array}{l}\text { homozygous } \\
\text { c.1394C }>\mathrm{T} \\
(\mathrm{p} . \text { Thr465Ile) }\end{array}$ \\
\hline $\begin{array}{l}\text { Case } 2 \text { [] } \\
\text { Age of OS: } 3 \text { mos } \\
\text { Age of Dx: } 6 \text { mos } \\
\text { DoD: } 2 \text { yrs }\end{array}$ & yes & $\begin{array}{l}\text { neuromotor } \\
\text { regression, } \\
\text { hypotonia, spastic } \\
\text { tetraparesis }\end{array}$ & $\begin{array}{l}10 \mathrm{nmol} \\
\mathrm{MU} / 17 \mathrm{~h} / \\
\mathrm{mg} \text { protein* }\end{array}$ & $\begin{array}{l}\text { T2 hyperintense signal changes in PWM, } \\
\text { posterior limb of internal capsule, brainstem } \\
\text { corticospinal tract and cerebellar dentate } \\
\text { nuclei. The enlargement of the prechiasmatic } \\
\mathrm{CN} \text { II and hypertrophy of the chiasmatic CN II. } \\
\text { Atrophy of corpus callosum. }\end{array}$ & $\begin{array}{l}\text { homozygous } \\
\text { c.411_413delTAA } \\
\text { (p.Lys139del) })^{10,11,12,13}\end{array}$ \\
\hline $\begin{array}{l}\text { Case } 3[\hat{]}] \\
\text { Age of OS: } 2 \text { mos } \\
\text { Age of Dx: } 8 \text { mos } \\
\text { DoD: } 13 \text { mos }\end{array}$ & no & $\begin{array}{l}\text { irritability, crying } \\
\text { and hypotonia, } \\
\text { spastic tetraparesis }\end{array}$ & $\begin{array}{l}12 \mathrm{nmol} \\
\mathrm{MU} / 17 \mathrm{~h} / \\
\mathrm{mg} \text { protein* }\end{array}$ & $\begin{array}{l}\text { T2 hyperintense signal changes in PWM, } \\
\text { PLIC, brainstem CST and cerebellar dentate } \\
\text { nuclei, enlargement of the prechiasmatic CN } \\
\text { II and hypertrophy of the chiasmatic CN II. } \\
\text { Atrophy of corpus callosum. }\end{array}$ & $\begin{array}{l}\text { homozygous } \\
\text { c.820G>C } \\
(\text { p.Glu274Gln })^{14}\end{array}$ \\
\hline $\begin{array}{l}\text { Case } 4[\hat{\jmath}] \\
\text { Age of OS: } 5 \text { mos } \\
\text { Age of Dx: } 7 \text { mos } \\
\text { DoD: } 10 \mathrm{mos}\end{array}$ & yes & $\begin{array}{l}\text { irritability, } \\
\text { incessant crying, } \\
\text { feeding difficulties, } \\
\text { neuromotor } \\
\text { regression }\end{array}$ & $\begin{array}{l}15 \mathrm{nmol} \\
\mathrm{MU} / 17 \mathrm{~h} / \\
\mathrm{mg} \text { protein* }\end{array}$ & $\begin{array}{l}\text { T2 hyperintense signal changes in PWM, } \\
\text { PLIC, brainstem CST and cerebellar dentate } \\
\text { nuclei. }\end{array}$ & $\begin{array}{l}\text { homozygous } \\
\text { exons } 11-17 \\
\text { IVS10del30kbp }\end{array}$ \\
\hline $\begin{array}{l}\left.\text { Case } 5 \text { [ }{ }^{\lambda}\right] \\
\text { Age of OS: } 5 \text { mos } \\
\text { Age of Dx: } 12 \text { mos } \\
\text { DoD: } 13 \text { mos }\end{array}$ & yes & $\begin{array}{l}\text { Irritability, } \\
\text { excessive crying. } \\
\text { feeding difficulties, } \\
\text { neuromotor } \\
\text { regression }\end{array}$ & $\begin{array}{l}10 \mathrm{nmol} \\
\mathrm{MU} / 17 \mathrm{~h} / \\
\mathrm{mg} \text { protein }\end{array}$ & $\begin{array}{l}\text { T2 hyperintense signal changes in PWM, } \\
\text { PLIC, brainstem CST and cerebellar dentate } \\
\text { nuclei. Cerebral atrophy, atrophy of corpus } \\
\text { callosum. }\end{array}$ & $\begin{array}{l}\text { homozygous } \\
\text { c.1623G }>\text { A } \\
\text { (p.Trp541Ter) } \\
\text { novel } \\
\text { present study }\end{array}$ \\
\hline $\begin{array}{l}\text { Case } 6\left[{ }^{\lambda}\right] \\
\text { Age of OS: } 2 \text { mos } \\
\text { Age of Dx: } 4 \text { mos } \\
\text { DoD: } 2 \text { yrs }\end{array}$ & no & $\begin{array}{l}\text { irritability, excessive } \\
\text { crying, hypotonia, } \\
\text { feeding difficulties }\end{array}$ & $\begin{array}{l}14 \mathrm{nmol} \\
\mathrm{MU} / 17 \mathrm{~h} / \\
\mathrm{mg} \text { protein* }\end{array}$ & $\begin{array}{l}\text { T2 hyperintense signal changes in centrum } \\
\text { semiovale, posterior internal capsule, } \\
\text { dentate nucleus, brainstem, enlargement of } \\
\text { the prechiasmatic CN II hypertrophy of the } \\
\text { chiasmatic CN II. Atrophy of corpus callosum. }\end{array}$ & $\begin{array}{l}\text { homozygous } \\
\text { c.1623G }>\text { A } \\
\text { (p.Trp541Ter) } \\
\text { novel } \\
\text { present study }\end{array}$ \\
\hline $\begin{array}{l}\text { Reported case } \# 1 \\
\text { Kardas et al. }{ }^{16}\left[{ }^{\imath}\right] \\
\text { Age of OS: } 3 \text { mos } \\
\text { Age of Dx: } 4 \text { mos } \\
\text { DoD:NA }\end{array}$ & yes & $\begin{array}{l}\text { irritability, crying, } \\
\text { poor head control, } \\
\text { convulsions }\end{array}$ & $\begin{array}{l}0.01 \mu \mathrm{mol} / \mathrm{g} / \mathrm{h} \\
(\mathrm{N}: 0.8-4)\end{array}$ & $\begin{array}{l}\text { Bilateral, symmetrical hyperintense signal } \\
\text { changes in cerebellar dentate nuclei and deep } \\
\text { white matter of the cerebral hemispheres. }\end{array}$ & $\begin{array}{l}\text { homozygous } \\
\text { c.727delT } \\
\left(\text { p.Leu243Serfs }{ }^{*} 8\right)^{16}\end{array}$ \\
\hline $\begin{array}{l}\text { Reported case } \# 2 \\
\text { Güngör et al. }{ }^{17}\left[{ }^{\Uparrow}\right] \\
\text { Age of OS: } 3 \text { mos } \\
\text { Age of Dx: } 4 \text { mos } \\
\text { DoD:NA }\end{array}$ & NA & $\begin{array}{l}\text { irritability, } \\
\text { hypotonia, poor } \\
\text { head control }\end{array}$ & $\begin{array}{l}6,5 \mathrm{nmol} / 17 \\
\mathrm{~h} / \mathrm{mg} \text { protein } \\
(\mathrm{N}: 18-115)\end{array}$ & $\begin{array}{l}\text { Enlargement of the prechiasmatic CN II } \\
\text { hypertrophy of the chiasmatic CN II, T2 } \\
\text { hyperintense signal changes in dentate nuclei, } \\
\text { the posterior limbs of the capsules and in the } \\
\text { deep PVM. }\end{array}$ & $\begin{array}{l}\text { homozygous } \\
\text { c.943delG } \\
\left(\text { p.Glu315Asnfs*10) }{ }^{17}\right.\end{array}$ \\
\hline $\begin{array}{l}\text { Reported case \#3 } \\
\text { Isık et al. }{ }^{13}\end{array}$ & NA & NA & NA & NA & $\begin{array}{l}\text { homozygous } \\
\text { c.411_413delTAA } \\
\left(\text { p.Lys139del) }{ }^{13}\right.\end{array}$ \\
\hline $\begin{array}{l}\text { Reported case \#4 } \\
\text { Tuncer et al. } .^{9}\left[{ }^{\Uparrow}\right] \\
\text { Age of OS:3 mos } \\
\text { Age of Dx: } 4 \text { mos } \\
\text { DoD:NA }\end{array}$ & yes & $\begin{array}{l}\text { irritability, crying, } \\
\text { hypotonia, spastic } \\
\text { tetraparesis, } \\
\text { convulsions }\end{array}$ & $\begin{array}{l}0.045 \mathrm{nmol} / \\
\mathrm{mg} / \mathrm{h}(\mathrm{N}: 0.60- \\
3.29)\end{array}$ & $\begin{array}{l}\text { T2 hyperintense signal changes in the PVM, } \\
\text { the cerebellar white matter, and the dentate } \\
\text { nucleus. }\end{array}$ & $\begin{array}{l}\text { homozygous } \\
\text { c.1394C>T } \\
\left(\text { p.Thr465Ile) }{ }^{9}\right.\end{array}$ \\
\hline
\end{tabular}

Dx: diagnosis, OS: Onset, DoD: Date of death, CM: Cousin marriage NA: not available

CN II: Optic Nerve, PWM: periventricular white matter, CST: corticospinal tract, PLIC (posterior limb of internal capsule)

Normal range of GALC enzyme activity in leukocytes: *25-105 nmol MU/17 h/mg protein 
mother noticed that she had sucking difficulties. At three months of age, she experienced crying and irritability. She was able to control her head and smile. Loss of previously acquired head control, visual tracking and hypotonia were noted at the time of evaluation at four months of age. She required feeding via nasogastric tube at five months. She died of respiratory insufficiency due to pneumonia at 14 months of age.

Case 2, female patient, the third child born to consanguineous parents, was delivered at term by NSVD. She had a healthy sister and a history of a deceased brother at 2 years of age who had hypotonia and feeding difficulties from birth and history of aspiration pneumonia at 5 months old with a preliminary diagnosis of neurodegenerative disease. At three months of age, she was developmentally normal. Head control and smiling were present. Thereafter, her development regressed and hypotonia developed. At the time of her first evaluation at 5 months of age, she also exhibited an absence of head control and spastic tetraparesis as well as tightly fisted hands. She responded to light but abilities such as focusing on an object or visual tracking of a moving object were not noted. She underwent hematopoietic stem cell transplantation (HSCT) for early-onset KD at 10 months of age. Her clinical course worsened progressively over the next months. She died at 2 years of age.

Case 3, male patient, the second child born to non-consanguineous parents from the same village, was delivered at term via cesarean section due to breech presentation. His older sister was healthy. Family history revealed a paternal cousin with the diagnosis of $\mathrm{KD}$ who died at the age of 11 months. His early development was unremarkable. At 2 months, he was admitted for pneumonia and soon after increased irritability, crying and hypotonia were noted. By the time of our initial evaluation at 5 months, he did not smile or interact. Neurological examination demonstrated truncal hypotonia, spastic tetraparesis and no head control. He died of aspiration pneumonia at 13 months of age.

Case 4, male born to a first cousin marriage; the second born child was delivered at term by cesarean section due to previously history of cesarean in the first pregnancy. At five months of age, he was developmentally normal. Subsequently, irritability, incessant crying, and feeding difficulties were noted. He was admitted to the intensive care unit for aspiration pneumonia. He lost acquired head control and smiling at 6 months of age. At the time of our evaluation at 7 months of age, he had severe hypotonia. No head control and smiling were present. He passed away due to aspiration pneumonia at 10 months of age.

Case 5, the first child of a consanguineous couple, was born at term via NSVD. Developmental milestones were normal until five months of age. At that time, he developed irritability and excessive crying. At nine months, he lost previously acquired milestones. Our neurologic examination at 10 months of age revealed remarkable irritability with generalized hypertonia. He required a gastrostomy tube placement at 11 months due to feeding difficulties. His clinical course worsened progressively over the next three months. The patient died at home at 13 months of age.

Case 6, the first child of a non-consanguineous couple from the same village, was born at term via NSVD. His family history was unremarkable. His early development was normal until 2 months of age. At two months, irritability and crying were noted. Thereafter, he developed feeding difficulties and reflux disease. At the time of our evaluation at 3 months of age, he had hypotonia and hypoactive deep tendon reflexes. No head control and eye control were present. At 1.5 years of age, he had to undergo a tracheostomy operation. He died of aspiration pneumonia at 2 years of age. 


\section{Mutation results}

Homozygous missense c.1394C $>\mathrm{T}$ (p.Thr465Ile) mutation in Case 1, homozygous 3-base c.411_413delTAA (p.Lys139del) deletion in Case 2, homozygous missense c.820G $>C$ (p.Glu274Gln) mutation in Case 3 and homozygousnonsensec.1623G $>$ A (p.Trp541Ter) variant in cases 5 and 6 were detected in GALC gene by next generation sequence analysis. 30 kilobase deletion mutation among the exons 1117 (IVS10del30kbp) was performed with GALC gene specific MLPA probes in Case 4, where no mutation was detected in sequence analysis (Fig. 2).

Point mutations in all cases with available DNA were confirmed by Sanger sequencing, whereas in case 3, who had insufficient DNA sample, maternal and paternal heterozygosity was demonstrated by Sanger sequencing as parents of case 2, case 5 and case 6 .

The novel c.1623G>A (p.Trp541Ter) variant has not been previously reported in the literature, but it was predicted to be pathological as it would lead to an early termination in the amino acid sequence by causing a stop codon. The parents of the cases were found to be heterozygous as expected for these mutations.

\section{Discussion}

In this study, we aimed to present the clinical, radiological, and molecular characteristics of six EOKD cases and to review the previously reported Turkish cases in the literature.

KD, which has both lethal and late-onset forms, is a relatively common storage disease in our country. It is most common in the Druze community living in northern Israel and in two Muslim-Arab villages close to Jerusalem. ${ }^{7}$ The estimated incidence of KD in Turkey was calculated as 1/100,000 in 2004 by Ozkara and Topcu. ${ }^{8}$ This incidence was found by proportioning 65 patients diagnosed with KD by postnatal enzyme activity test to 6.500 .000 babies born alive between 1997-2002. According to this study, KD is the 3rd disease, after Metachromatic leukodystrophy (MLD) and GM2 gangliosidosis among sphingolipidoses with an incidence of 1.00. GALC gene molecular analysis has not been used widely in our country for many years, due to the efficient use of GALC enzyme activity for the pre- and postnatal diagnosis of KD. Unfortunately, the low galactocerebrosidase activity is unable to reliably predict the phenotype. For this reason, determining the genotypes of all cases diagnosed with low enzyme activity is especially important in terms of establishing a genotype-phenotype relationship other than genetic counseling to be given to family members under carrier risk.

As in our cases, the common initial symptoms of EOKD were excessive crying, extreme irritability, feeding difficulties complicated with gastroesophageal reflux, spasticity, developmental regression (loss of acquired milestones such as smiling, and head control), hypotonia and seizures. Previously EOKD diagnosed siblings and/or relatives (in Cases 1, 2 and 3), and the history of consanguineous marriage (in Case 1, Case 2 and Case 4) are also supportive.

The radiological findings of EOKD include in T2-weighted images of MRI commonly shows demyelination with increased T2 signaling in the deep periventricular white matter along with posterior limb of the internal capsule (PLIC), and brainstem corticospinal tract, dentate and cerebellar white matter. Occasionally optic nerve/chiasma hypertrophy and T2 hyperintensity and/or atrophy of the corpus callosum may be seen. All our cases had characteristic radiological involvement. The enlargement of the prechiasmatic cranial nerve II and hypertrophy of the chiasmatic cranial nerve II were found in Cases 2, 3 and 6. Volume loss and severe involvement in the midbrain were found in Case 1.

The mutations found in our case series were comparable to the literature in terms of genotype-phenotype correlation. The mutation of c.1394C $>\mathrm{T}$ (p.Thr465Ile) mutation in Case 


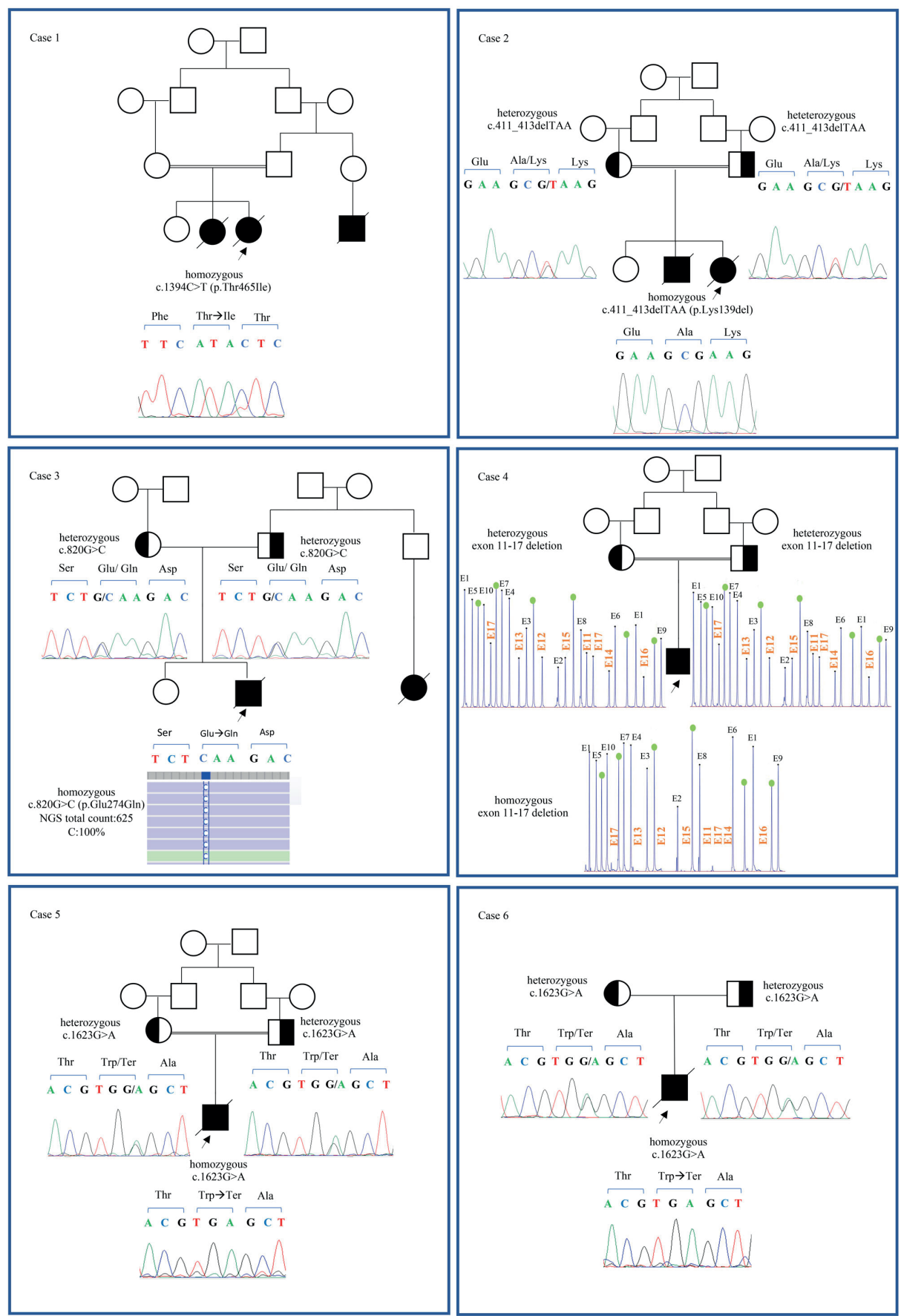

Fig. 2. Molecular findings of our cases.

Point mutations in Case 1, Case 2, Case 5 and Case 6 were confirmed by Sanger sequencing. Maternal and paternal heterozygosity of Case 2, Case 3, Case 5 and Case 6 was demonstrated by sanger sequencing. The frameshift mutation of c.411_413delTAA (p. Lys139del) in Case 2 results in one missing amino acid. Because of the two consecutive lysine amino acids in the codon reading frame, these three base deletions cause the loss of a single amino acid. Homozygous missense c.820G $>$ C (p.Glu274Gln) mutation in Case 3 was detected by NGS. Homozygous 30 kilobase deletion mutation among the exons 11-17 (IVS10del30kbp) in case 4 and heterozygosity of his parents were performed with GALC gene specific MLPA probes (green dots for reference peaks). 
1 was first reported as homozygous in three Turkish siblings affected by EOKD disease in 2018 by Tuncer et al. ${ }^{9}$ Our case had classic EOKD, with a complicated course with hydrocephalus and severe midbrain involvement. Our results in addition to the previously reported cases indicate that the homozygosity of this mutation may be related to EOKD. Although there are few Turkish reported cases, the second representation of this mutation suggested that it might be a relatively common mutation in our population.

The mutation of c.411_413delTAA (p. Lys139del) in Case 2 was also reported in a Turkish patient with LOKD in 2012, as a compound heterozygous with c.200C $>\mathrm{T}$ (p.Thr67Ile) mutation. ${ }^{10}$ Similarly, this mutation was reported as combined heterozygous with c.1829A> C (p.Asp610Ala) mutation in two Greek siblings with LOKD in 2015. ${ }^{11}$ Homozygosity of this mutation has been reported in cases with three early-onset findings, two of which were Greek and the remaining one was Turkish. ${ }^{11-13}$ In addition to the previous reports of compound heterozygous cases with late-onset $\mathrm{KD}$, the homozygosity leading to infantile-onset disease in our cases demonstrates that the homozygosity of this mutation leads to more severe disease. This mutation can be seen in Turkish cases as well as in the Greek population. Moreover, the identification of optic nerve growth accompanying classical MRI findings in our case underlined the fact that the diagnosis of KD should be considered in the presence of a neurodegenerative course.

The homozygous missense c.820G $>C$ (p.Glu274Gln) mutation found in Case 3 was first detected in a case in the EOKD screening program in the USA in 2016. ${ }^{14}$ This is the first time that this mutation is being reported in the Turkish population. A 30 kilobase deletion mutation among the exons 11-17 (IVS10del30kbp) was found in Case 4. This was not an unexpected finding, as it is the most common mutation in the European population.

Importantly, the c.1623G $>$ A mutation detected in Cases 5 and 6 was not previously reported in the literature and was predicted as pathogenic, because it codes a stop codon in the amino acid sequence. Consistently, the c. $1622 \mathrm{G}>\mathrm{A}$ mutation in the same codon was previously reported in a combined heterozygous case from Morocco. ${ }^{15}$ It strengthens the pathological interpretation of this variant, as it also codes a stop codon (p.Trp541Ter) as in our case.

When the literature and HGMD database were scanned for Turkish cases with KD, it was seen that mutations c.727delT (p.Leu243Serfs*8) and c.943delG (p.Glu315Asnfs*10) were reported, which were not seen in our case series. The c.727delT (p.Leu243Serfs*8) mutation was reported by Kardas et al. in 2013 in a 4-monthold case affected by the EOKD. ${ }^{16}$ The c.943delG (p.Glu315Asnfs*10) mutation was defined as previously unidentified homozygous in an infantile-onset KD patient with enlargement in the optic chiasm in $2016 .{ }^{17}$

All our cases died before reaching the age of three despite all the proper care and medical treatment. Unfortunately, all of the currently available treatment options are beneficial only for early diagnosed individuals. ${ }^{18,19}$ The better identification of GALC genotypes is important, because emerging treatment options, such as bone marrow transplantation or HSCT, can slow the progression of KD when applied in the early phase of the disease. ${ }^{18}$ Measuring enzyme activity on dried blood specimens (DBS) is a well-established screening method and is currently being used in some states of the USA. ${ }^{18}$ Defective enzyme activity results obtained from neonatal screening tests of dried blood samples should be confirmed by the leukocyte enzyme assay. ${ }^{19}$ Low GALC enzyme activity is evaluated in DBS, will detect infantile or late-onset Krabbe patients before the symptoms begin, as well as to detect healthy individuals with pseudo-deficiency alleles that 
cause a decrease in GALC enzyme activity. In asymptomatic cases with positive first-line tests, the detection of toxic psychosine levels and screening of population specific common mutations or sequencing of the entire GALC gene are used for the definitive diagnosis of KD. At this stage, knowledge of which combination of mutations causes infantile or late-onset phenotype is also particularly important for the timing of treatment options. In addition, the presence of variants in the GALC gene, such as p.Arg184Cys, p.Asp248Asn and p.Ile562Thr that cause pseudo-deficiency allele in the community also makes the interpretation of this test easier. ${ }^{20}$ The Newborn Screening Programme (NSBP) in Turkey, ongoing for over 30 years with the aim of preventing morbidities and reducing the mortality rate of manageable conditions with early treatment, has slightly expanded and recently included phenylketonuria, congenital hypothyroidism, biotinidase deficiency and cystic fibrosis. Because of the high incidence of consanguineous marriage and inherited metabolic disorders, an expanded NBSP is essential for Turkey.

There are some limitations to our study. Our study size is limited. We report only one new disease-generating mutation here, further studies are needed in order to better define the genetic spectrum of KD in Turkey. In one case (Case 3) the mutation detected by NGS could not be confirmed by Sanger analysis due to insufficient DNA sample. However, maternal and paternal heterozygosity demonstrated by Sanger sequencing indirectly supported NGS results.

In conclusion, with the prediction that newborn screening tests will expand soon, a better understanding of the disease-causing mutations specific to the Turkish population is of utmost importance. To this end, our results expand the known mutation spectrum of KD in our population. However, further studies are needed to broaden the knowledge on diseasecausing mutations.

\section{Ethical approval}

The study was reviewed and approved by the Bezmialem Vakıf University, institutional review board, and written informed consent was obtained from all parents of the patients included in the study (No/Date: 54022451050.05.04/05.02.2019).

\section{Author contribution}

The authors confirm contribution to the paper as follows: study conception and design: ADA, GY; data collection: ADA, EŞ, ABK, ED; analysis and interpretation of results: ADA, AA, Aİ, GY; draft manuscript preparation: ADA, GY. All authors reviewed the results and approved the final version of the manuscript.

\section{Source of funding}

The authors declare the study received no funding.

\section{Conflict of interest}

The authors declare that there is no conflict of interest.

\section{REFERENCES}

1. Tappino B, Biancheri R, Mort M, et al. Identification and characterization of 15 novel GALC gene mutations causing Krabbe disease. Hum Mutat 2010; 31: E1894-E1914. https://doi.org/10.1002/ humu. 21367

2. Wenger DA, Suzuki K, Suzuki Y, Suzuki K. Galactosylceramide lipidosis: globoid cell leukodystrophy (Krabbe disease). In: Scriver CR, Beaudet AL, Sly WS, et al (eds). The Metabolic and Molecular Basis of Inherited Disease (8th ed). New York: McGraw-Hill, 2001: 3669-3694.

3. Abdelhalim AN, Alberico RA, Barczykowski AL, Duffner PK. Patterns of magnetic resonance imaging abnormalities in symptomatic patients with Krabbe disease correspond to phenotype. Pediatr Neurol 2014; 50: 127-134. https://doi.org/10.1016/j. pediatrneurol.2013.10.001 
4. Kleijer WJ, Keulemans JL, van der Kraan M, et al. Prevalent mutations in the GALC gene of patients with Krabbe disease of Dutch and other European origin. J Inherit Metab Dis 1997; 20: 587-594. https:// doi.org/10.1023/A:1005315311165

5. Wenger DA, Rafi MA, Luzi P. Molecular genetics of Krabbe disease (globoid cell leukodystrophy): diagnostic and clinical implications. Hum Mutat 1997; 10: 268-279. https://doi.org/10.1002/(SICI)10981004(1997)10:4<268::AID-HUMU2>3.0.CO;2-D

6. Xu C, Sakai N, Taniike M, Inui K, Ozono K. Six novel mutations detected in the GALC gene in 17 Japanese patients with Krabbe disease, and new genotypephenotype correlation. J Hum Genet 2006; 51: 548-554. https://doi.org/10.1007/s10038-006-0396-3

7. Rafi MA, Luzi P, Zlotogora J, Wenger DA. Two different mutations are responsible for Krabbe disease in the Druze and Moslem Arab populations in Israel. Hum Genet 1996; 97: 304-308. https://doi. org/10.1007/BF02185759

8. Ozkara HA, Topçu M. Sphingolipidoses in Turkey. Brain Dev 2004; 26: 363-3666. https://doi. org/10.1016/j.braindev.2003.09.006

9. Tuncer FN, Iseri SAU, Yapici Z, Demir M, Karaca M, Calik M. A novel homozygous GALC variant has been associated with Krabbe disease in a consanguineous family. Neurol Sci 2018; 39: 21232128. https://doi.org/10.1007/s10072-018-3556-2

10. Debs R, Froissart R, Aubourg P, et al. Krabbe disease in adults: phenotypic and genotypic update from a series of 11 cases and a review. J Inherit Metab Dis 2013; 36: 859-868. https://doi.org/10.1007/s10545-0129560-4

11. Dimitriou E, Cozar M, Mavridou I, Grinberg D, Vilageliu L, Michelakakis H. The spectrum of Krabbe disease in Greece: biochemical and molecular findings. JIMD Rep 2016; 25: 57-64. https://doi. org/10.1007/8904_2015_457

12. Vargiami E, Papathanasiou E, Batzios S, et al. Neuroradiological, neurophysiological and molecular findings in infantile Krabbe disease: two case reports. Balkan J Med Genet 2016; 19: 85-90. https://doi.org/10.1515/bjmg-2016-0011
13. Isik E, Onay $\mathrm{H}$, Atik $\mathrm{T}$, et al. Clinical utility of a targeted next generation sequencing panel in severe and pediatric onset Mendelian diseases. Eur J Med Genet 2019; 62: 103725. https://doi.org/10.1016/j. ejmg.2019.103725

14. Saavedra-Matiz CA, Luzi P, Nichols M, Orsini JJ, Caggana M, Wenger DA. Expression of individual mutations and haplotypes in the galactocerebrosidase gene identified by the newborn screening program in New York State and in confirmed cases of Krabbe's disease. J Neurosci Res 2016; 94: 1076-1083. https:// doi.org/10.1002/jnr.23905

15. Zerkaoui M, Ratbi I, Castellotti B, et al. A. Clinical and molecular report of novel GALC mutations in Moroccan patient with Krabbe disease: case report. BMC Pediatr 2015; 15: 182. https://doi.org/10.1186/ s12887-015-0490-9

16. Kardas F, Uzak AS, Hossain MA, Sakai N, Canpolat M, Yikılmaz A. A novel homozygous GALC mutation: very early onset and rapidly progressive Krabbe disease. Gene 2013; 517: 125-127. https://doi. org/10.1016/j.gene.2012.12.040

17. Güngör $O$, Güngör G, Özkaya AK, Dilber C, Aydın $\mathrm{K}$. A new mutation in an infant with Krabbe disease accompanied by enlargement of the optic nerves. Acta Neurol Belg 2017; 117: 319-321. https://doi. org/10.1007/s13760-016-0637-y

18. Escolar ML, Poe MD, Provenzale JM, et al. Transplantation of umbilical-cord blood in babies with infantile Krabbe's disease. New Engl J Med 2005; 352: 2069-2081. https://doi.org/10.1056/ NEJMoa042604

19. Wenger DA, Escolar ML, Luzi P, Rafi MA. Krabbe disease (Globoid Cell Leukodystrophy). In: Valle DL, Antonarakis S, Ballabio A, Beaudet AL, Mitchell GA (eds). The Online Metabolic and Molecular Bases of Inherited Disease. McGraw Hill, 2019. https://doi. org/10.1036/ommbid.178

20. Madsen AMH, Wibrand F, Lund AM, Ek J, Dunø M, Østergaard E. Genotype and phenotype classification of 29 patients affected by Krabbe disease. JIMD Rep 2019; 46: 35-45. https://doi.org/10.1002/jmd2.12007 